\title{
BIMBINGAN DAN KONSELING ISLAM SOLUSI MENJAGA DAN MENINGKATKAN KESEHATAN MENTAL
}

\author{
APREZO PARDODI MABA \\ Intitut Agama Islam Ma'arif Nahdlatul Ulama (IAIMNU) Metro Lampung \\ Email : aprezopm@gmail.com
}

\begin{abstract}
Islamic guidance and counseling in Indonesia has existed since first pesantren established, but at that time, had not known the term of "guidance and counseling". The practice tended to be implicit in many cultural practices which characterized by therapeutic relationship. Along with the inclusion of guidance and counseling in Indonesia, which later developed rapidly, there was arised awareness of the limitations and contradictions of some western approaches to the Islamic values, then the world and Indonesian muslim experts in guidance and counseling began to develop a new approach called Islamic guidance and counseling. Present day, Islamic guidance and counseling has become one of the most effective approaches to alleviate various problems to restore and maintain counselee mental health.
\end{abstract}

Keywords: islamic guidance and counseling, mental health, solution.

Abstrak : Bimbingan dan Konseling islam di Indonesia sudah ada sejak pesantren di dirikan, hanya saja pada saat itu belum mengenal istilah bimbingan dan konseling. Praktiknya cenderung implisit dalam berbagai praktek budaya yang ditandai dengan adanya hubungan terapiutik. Seiring masuknya keilmuan bimbingan dan konseling di Indonesia, yang kemudian hari berkembang dengan pesat, muncul kesadaran akan adanya keterbatasan dan pertentangan beberapa pandangan pendekatan barat dengan ajaran Islam, maka para pakar mulai membangun sebuah pendekatan baru yang disebut dengan bimbingan dan konseling islam. Hingga saat ini, bimbingan dan konseling islam menjadi salah satu pendekatan yang efektif mengentaskan berbagai masalah untuk menjaga kesehatan mental konseli.

Kata Kunci : bimbingan dan konseling islam, kesehatan mental, solusi.

\section{Pendahuluan}

Dalam konteks satuan pendidikan, bimbingan dan konseling merupakan upaya sistematis, objektif, logis dan berkelanjutan serta terprogram yang dilakukan oleh konselor atau guru Bimbingan dan Konseling untuk memfasilitasi perkembangan peserta didik atau konseli untuk mencapai kemandirian dalam kehidupannya (Indonesia, 2014). Sehingga, Bimbingan dan Konseling seyogyanya dilakukan oleh guru Bimbingan dan Konseling atau Konselor yang telah mendapat pendidikan dan pelatihan untuk melakukan upaya tersebut dalam satuan pendidikan.

Dengan bekal pengetahuan dan keterampilan yang dimilikinya, ekspektasi kinerja Guru Bimbingan dan Konseling atau Konselor sangat mungkin untuk dicapai, mengingat berbagai hambatan kinerja yang dialami oleh Guru Bimbingan dan Konseling atau Konselor dalam satuan pendidikan begitu banyak. Kamaruszzaman menyebutkan, setidaknya ada 12 hambatan yang ditemui dalam implementasi layanan Bimbingan dan Konseling (1) Kepribadian dan dedikasi; (2) latar belakang pendidikan; (3) pengalaman; (4) keadaan kesehatan guru; (5) motivasi kerja; (6) kompetensi guru BK; (7) kedisiplinan kerja di sekolah; (8) sarana dan prasarana; (9) kepala sekolah; (10) sertifikasi; (11) keadaan kesejahteraan ekonomi guru; (12) organisasi profesi (Kamaruzzaman, 2017). 
Oleh karena itu, pelaksanaan layanan Bimbingan dan Konseling di Sekolah sudah seharusnya dilakukan oleh Guru Bimbingan dan Konseling atau Konselor yang memiliki kompetensi sesuai dengan bidang Bimbingan dan Konseling sehingga dapat mengoptimalkan kinerjanya. Demikian pula kepala sekolah, guru mata pelajaran dan guru Bimbingan dan Konseling atau Konselor merupakan komponen intergral yang dituntut untuk bekerja sama dan saling melengkapi dalam upaya membantu peserta didik atau konseli mencapai perkembangan optimal (K. P. dan Kebudayaan \& Kependidikan, 2016).

Dalam upaya pencapaian tujuan pendidikan, telah disusun Standar Kompetensi Lulusan (SKL) dalam Bimbingan dan Konseling lebih dikenal dengan istilah Standar Kompetensi Kemandirian Peserta Didik (SKKPD) yang mencakup 10 aspek perkembangan pada SD dan SMP serta 11 aspek perkembangan pada SMA (D. P. dan Kebudayaan, 2007). Salah satu dari aspek perkembangan tersebut adalah landasan hidup religius, aspek perkembangan ini harus dicapai oleh peserta didik atau konseli agar mampu tumbuh dan berkembang secara optimal sebagai bekal untuk menjalani kehidupan.

Salah satu pendekatan yang dapat dilakukan untuk membantu peserta didik atau konseli agar dapat memenuhi landasan hidup religius adalah dengan Bimbingan dan Konseling Agama. Disebut demikian karena menggunakan Agama sebagai pendekatan dalam proses pemberian layanan Bimbingan dan Konseling.

Sebagian besar konseli yang pernah mendapatkan layanan konseling memiliki dasar keyakinan spiritual dan agama (Henriksen, Polonyi, Bornsheuer-Boswell, Greger, \& Watts, 2015). Khususnya Negara Kesatuan Republik Indonesia, negara yang berlandaskan kepada Ketuhanan yang Maha Esa, maka setiap Warga Negara dapat dipastikan mengimani Tuhan yang Maha Esa. Berdasarkan keadaan tersebut maka Bimbingan dan Konseling Agama menjadi solusi tepat untuk membekali konseli dengan pemahaman religius agar kelak dapat berkembang menjadi manusia yang beriman dan bertaqwa kepada Tuhan yang Maha Esa.

\section{Bimbingan dan Konseling Agama}

Sebelum mendefinisikan bimbingan dan konseling agama, akan lebih baik jika penulis memaparkan apa yang melatari munculnya bimbingan dan konseling agama. Sehingga, kita dapat melihat konteksnya dalam pelaksanaan bimbingan dan konseling agama saat ini.

Bimbingan dan konseling Agama lahir karena keterbatasan konsep yang dimiliki oleh pendekatan-pendekatan konseling barat yang bersifat spekulatif dan tentatif (belum tentu, sementara waktu dan masih bisa berubah) (Sutoyo, 2013). Selain itu, adanya pengakuan bahwa setiap individu memiliki dimensi spiritual yang dipercaya dapat memberikan jalan untuk memberikan motivasi kepada konseli dalam menghadapi kendala hidup sehari-hari (Subhi, 2016).

Konsep spiritualitas dan agama mulai diintegrasikan dalam konseling sejak tahun 1990an dan terus berkembang hingga saat ini (Parker, 2011), bahkan menjadi salah satu elemen penting yang menjadi perhatian dalam bidang keilmuan kesehatan mental (Brown, Carney, Parrish, \& Klem, 2013). Meskipun pada awal abad 19 James, Freud dan Jung masih memperdebatkan kelayakan integrasi agama dan spiritual ke dalam proses konseling dan terapi (Robert \& Kelly, 2015). Akhrinya tak bisa dihindari, hingga saat ini spiritualitas dan agama masih menjadi polemik para pakar karena dimensi spiritual yang dimaksud tidak dapat diukur secara kuantitatif dan dibuktikan keberadaannya (Burke, Chauvin, \& Miranti, 2005). Perbedaan pandangan tersebut berdampak pada belum adanya konsensus para pakar 
mengenai definisi spiritual dan agama selain karena dimensinya yang tidak kasat mata, juga disebabkan oleh beberapa kesamaan karakteristik menyulitkan memberi definisi yang jelas tentang keduanya (Cornish \& Wade, 2010).

Untuk kepentingan penulisan artikel ini, maka penulis meminjam konsep spiritual Rick Johnson, ia megatakan bahwa, spiritualitas membantu individu berpindah dari posisi sempit dan egosentris ke perasaan terhubung dengan semesta alam dan kekuatan Ilahiah atau tujuan yang lebih besar (Johnson, 2013). Spiritual dimaknai sebagai media yang membuat seseorang mengakui diri bahwa ia adalah hamba dari Sang Pencipta yang dilahirkan dengan tujuan yang mulia.

Demikian juga definisi agama, pada umumnya Barat menganggap agama sebagai sistem praktik dan kepercayaan kepada Tuhan. Seperti definisi Schilbrack mengenai agama, ia mengatakan bahwa agama merupakan suatu ritual yang apabila dilakukan maka orang tersebut akan mendapatkan imbalan kebaikan (Schilbrack, 2013). Pendapat tersebut dibantah oleh Sauchelli dalam artikel yang berjudul The Definition of Religion, Super-empirical Realities and Mathematics, ia mengatakan bahwa pendapat tersebut tidak berdasar (Sauchelli, 2016). Pandangan tersebut menggunakan pesfektif ontologi, yang menekankan definisi agama pada praktiknya saja. Dengan begitu, aspek transendensi dan hubungan dengan yang Maha Kuasa diabaikan. Oleh karena itu, definisi agama menggunakan sudut pandang ontologi tidak bisa diterima.

Sementara, Timur menekankan agama kepada hubungan transendensial atau pembebasan, yang bertentangan dengan sistem kepercayaan Barat. Banyak definisi agama telah diajukan para pakar, namun penulis akan mengutip definisi agama menurut Peregrine Murphy Kavros, agama mencakup doktrin (kepercayaan keyakinan atau akidah), mitos (kisah suci yang bersejarah), etika (kesucian moral atau akhlak mulia), ritual (shalat, sembahyang, penggunaan benda-benda sakral atau upacara, termasuk pengorbanan yang dilakukan oleh orang-orang suci atau nabi atau rosul), pengalaman (kebaktian dan pengalaman mistis), dan institusi sosial (pendidikan, pertemuan sosial, pelayanan sosial) yang kesemuanya saling terkait (Leeming, 2014, hlm. 1492).

Setelah menempatkan spiritual dan agama pada posisi yang seharusnya, maka kita akan segera sampai pada pengertian Bimbingan dan Konseling Agama. Seperti yang telah dijelaskan sebelumnya, Bimbingan dan Konseling merupakan upaya membantu peserta didik atau konseli mencapai kemandirian dan aktualisasi diri. Jadi, Bimbingan dan Konseling Agama adalah upaya sistematis, objektif, logis, terprogram dan berkelanjutan untuk memfasilitasi konseli untuk mencapai kemandirian dan aktualisasi dengan menggunakan agama dan ajarannya sebagai dasar untuk memahami konseli dan membantu konseli mengentaskan masalahmasalahnya.

\section{Bimbingan dan Konseling Islam}

Setelah sebelumnya mengumpulkan dan menelaah berbagai sumber, sekarang kita telah mendapatkan definisi bimbingan dan konseling agama. Setiap agama memiliki cara pandangannya masing-masing tentang bimbingan dan konseling, namun dalam tulisan ini secara khusus kita akan membicarakan bimbingan dan konseling islam.

Bimbingan adalah suatu upaya yang diberkan kepada seseorang dilakukan secara terus menerus dan sistematis agar mampu mencapai kemandirian dalam memahami diri untuk seterusnya mengaktualisasikan diri sebagai usaha menuju tingkat perkembangan optimal dan mampu menyesuaikan diri dengan lingkungan 
(Rohman, 2016). Sementara, Istilah konseling merupakan terjemahan dari counseling (Amerika) atau counselling (British) yang berasal dari kata consilium (Latin) yang berarti nasehat, informasi, percakapan atau pertimbangan yang diberikan seseorang kepada orang lain untuk membantu membuat keputusan yang biasa dikaitkan dengan kata bimbingan, sehingga muncul istilah bimbingan dan konseling(Lubis, 2011).

Dalam artikel yang berjudul Islamic Approach in Counseling, Hamjah dan Akhir menyebutkan tiga komponen utama dalam islam yang dipakai dalam konseling, meliputi akidah sebagai dasar kepercayaan, akhlak mulia sebagai sarana untuk berkomunikasi dengan sesama manusia yang menentukan baik buruknya perilaku dan ibadah ritual sebagai sarana komunikasi transendensial kepada Allah SWT(Hanin Hamjah \& Mat Akhir, 2014). Ketiga komponen inilah yang menjadi pedoman dalam melaksanakan praktik bimbingan dan konseling islam, apabila salah satunya tidak dicapai maka akan menjadi masalah. Sehingga ketiganya harus dicapai secara beriringan dengan demikian individu dianggap telah mencapai kematangan, mandiri dan berada pada proses aktualisasi diri.

Dalam bukunya yang berjudul Bimbingan dan Konseling Islam Teori dan Praktik, Anwar Sutoyo mendefinisikan bimbingan dan konseling islam sebagai upaya membantu individu untuk mengembangkan fitrahnya dengan cara memberdayakan iman, akal dan kemauan yang dilimpahkan oleh Allah kepadanya, agar fitrah yang sejatinya sudah ada pada individu tersebut dapat berkembang sesuai dengan ajaran islam (Sutoyo, 2013).

Maka, jika harus mendefinisikan bimbingan dan konseling islam berdasarkan dari apa yang sudah dipaparkan diatas, bimbingan dan konseling islam merupakan suatu layanan yang diberikan secara sistematis dan berkelanjutan untuk mengembangkan dan menguatkan akidah, akhlak dan ibadah individu yang dicirikan adanya hubungan konseli dan konselor.

Saat ini ada dua bentuk bimbingan dan konseling islam, yang pertama nilainilai islam di integrasikan dalam bimbingan dan konseling atau yang kedua, bimbingan dan konseling islam sebagai suatu pendekatan sehingga memiliki makna yang sama dengan behaviouristik, psikoanalisis, psikologikal, sistematik relasional dan kontekstual (Prihananto, 2014). Melihat berbagai perkembangan konsep bimbingan dan konseling islam saat ini, maka pilihan yang kedua adalah pilihan yang harus diambil. Bimbingan konseling islam menjadi sebuah disiplin ilmu, disiplin ilmu yang dituntut untuk mampu mengakomodasi berbagai perubahan yang terjadi di masyarakat. Seperti yang diungkapkan oleh Abdullah Somaya, bahwa konseling islam menjadi diskursus formal yang sebanding dengan paradigma mainstream barat (Abdullah, 2009).

\section{Model Bimbingan dan Konseling Islam}

Bimbingan dan konseling islam jika dibandingkan dengan bimbingan dan konseling barat, dapat diangkat satu kesimpulan bahwa bimbingan dan konseling islam lebih menekankan sisi pencegahan sementara barat lebih berfokus kepada sisi kuratifnya (S. S, 2011). Namun, bukan berarti bimbingan dan konseling islam tidak memperhatikan upaya pengentasan masalah.

Abdullah Somaya dalam artikelnya yang berjudul Islamic Counseling and Psychotherapy Trends in Theory Development mengatakan jika di lihat dari perspektif budaya islam maka proses konseling tidaklah ditampilkan secara eksplisit, namun menjadi bagian dalam praktik penyembuhan. Masalah-masalah kesehatan mental yang terjadi pada manusia merupakan akibat dari gangguan dari jin atau 
makhluk halus. Untuk mengatasi masalah tersebut maka dilakukanlah ritual yang memungkinkan untuk berkomunikasi dengan dunia ghaib. Upaya pengentasan masalahnya bisa dilakukan dengan membaca al-qur'an, berdoa, atau meminta bantuan orang shaleh untuk mendoakan supaya jin atau makhluk halusnya tidak mengganggu lagi, hasilnya cukup efektif orang-orang yang mengalami gangguan kesehatan mental tersebut sehat dan kembali beraktifitas seperti biasa. Dari contoh kasus diatas, jelas bahwa ajaran islam efektif dalam membantu orang yang mengalami masalah kesehatan mental (Abdullah, 2009).

Sementara, Mohd Djawad Dahlan pernah menuliskan bahwa di Indonesia proses konseling sudah ada sejak dulu, sejak pertama kali pesantren di dirikan, namun pada saat itu belum belum mengenenal istilah konseling. Para kiyai yang sekaligus berperan sebagai pengasuh pesantren menjadi tempat masyarakat mengajukan berbagai pertanyaan mengenai masalah ekonomi, kecemasan, konflik dalam keluarga, jodoh dan lain-lain (Djawad Dahlan, 1985). Dengan demikian, perasaan bahagia selalu meliputi setiap orang yang pulang setelah bertemu kiyai karena permasalahan mereka mendapatkan solusi.

Jika perhatikan, kedua praktik pemberian bantuan diatas memiliki karakteristik yang sama dengan konseling modern, antara penolong (kiyai atau orang yang mendoakan) memiliki hubungan terapiutik dan terjadi proses interaktif dengan orang yang di tolong. Apabila percakapan tersebut dilakukan dalam ruangan antara konselor (yang telah memenuhi kualifikasi akademik) dan konseli yang bertujuan untuk mengentaskan suatu masalah, maka hubungan terapiutik tersebut dapat disebut dengan layanan konseling islam.

Inayat menjelaskan tujuan konseling islam adalah menyerahkan diri sepenuhnya kepada Allah SWT kemudian mengevaluasi diri untuk menjadi pribadi yang lebih baik (Inayat, 2010). la membagi konseling islam menjadi tiga tahap, yakni:

a. Awalan: menyiapkan seseorang untuk terhubung kepada Allah, mengeksplorasi masalah, fokus pada masalah yang spesifik dan menyampaikan nilai-nilai inti.

b. Inti: menguatkan pertalian dengan Sang Pencipta, menelusuri kembali masalah, menjaga hubungan terapiutik, melakukan proses konseling sesuai kesepakatan, menumbuhkan kemampuan konseli untuk melakukan kebaikan.

c. Pengakhiran: menginisiasi konseli untuk berkembang, menguatkan kembali pertalian dengan Sang Pencipta, fokus pada menumbuhkan potensi konseli, menentukan perubahan yang tepat, mengimplementasikan perubahan dan mengakhiri hubungan konseling.

Namun, perdebatan mengenai bagaimana model bimbingan dan konseling islam masih menjadi isu yang hangat untuk dibahas. Jafari menolak islamisasi pendekatan konseling materialistik sekuler yang banyak ditemui dalam pendekatan konseling barat (Zayed, 2017). Sebaliknya, Abu Raiya mengklaim kemungkinan bahwa beberapa pandangan Freud dan Jung dalam teori kepribadian yang mereka susun berasal dari al'qur'an (Abu-Raiya, 2014). Dengan demikian, pengembangan keilmuan khususnya bimbingan dan konseling islam harusnya bukan islamization of term or word namun islamization of knowledge, konkritnya hal merupakan upaya membangun paradigma baru yang efektif dalam bimbingan dan konseling dengan menjadikan al Qur'an dan Hadits sebagai rujukan (Prihananto, 2014).

\section{Kesehatan Mental menurut Islam}

Dunia ini merupakan tempat yang penuh dengan hal yang dapat membuat 
jiwa menjadi tegang dan tidak ada cara untuk menghindarinya, yang ada adalah bagaimana kita mampu menghadapi untuk meredakannya (Baqutayan, 2011). Mental yang sehat adalah keberhasilan mengatasi kegelisahan hati yang dilakukan dengan berani dan percaya diri untuk mendapatkan ketenangan jiwa. Kesehatan mental memiliki hubungan erat dengan kesejahteraan dan kebahagiaan manusia (Lubis, 2011). Oleh karena itu, sehat mental merupakan modal penting bagi manusia untuk mencapai aktualisasi diri. Agar bisa menjadi pribadi dengan mental yang sehat kita harus mampu mengatur diri dalam hubungannya dengan diri sendiri, orang lain, lingkungan dan Allah SWT (Anwar, 2015).

Namun, menurut Abu Hamid Muhammad al-Ghazali, orang-orang yang kesehatan mentalnya terganggu adalah orang yang jauh dari Allah (Keshavarzi \& Haque, 2013). Oleh karena itu, kesehatan mental seseorang sangat tergantung kepada kedekatannya dengan Allah SWT. Jika menggunakan standar diatas, maka pekerjaan yang sesuai dengan harapan, kebahagiaan dalam rumah tangga, kehidupan sosial yang baik dan kebahagiaan duniawi yang lain tidak cukup untuk mencapai kesehatan mental. Perlu upaya yang sungguh-sungguh untuk mendekatkan diri kepada Allah SWT dengan mencontoh yang telah diajarkan oleh Nabi Muhammad SAW dalam berpikir, bertindak dan bersikap yang dapat dipelajari dalam al-qur'an dan hadits.

\section{Urgensi Bimbingan dan Konseling Islam}

Pada era globalisasi saat ini, masyarakat muslim harus dihadapkan dengan persoalan yang sangat berat karena pluralisme, perubahan yang begitu cepat dari ilmu pengetahuan dan teknologi. Serta hilangnya jarak yang selama ini memisahkan satu dan yang lain karena kemudahan berkomunikasi (Lubis, 2011). Keadaan ini tidak dapat dihindari lagi, masyarakat muslim harus mampu menyesuaikan diri dengan tuntutan yang muncul bersama globalisasi. Supriadi menjelaskan setidaknya ada tujuh perubahan yang terjadi, berikut adalah perubahan yang dimaksud 1) transformasi masyarakat Indonesia 2) dampak reformasi terhadap pendidikan 3) teori tentang otak dan pengaruhnya terhadap dunia pendidikan 4) teori tentang kecerdasan intelektual, emosional dan spiritual 5) menguatnya kembali aliran hereditarianisme 6) menguatnya multikulturalisme dan 7) memanasnya kembali gesekan dan bahkan polarisasi peradaban (Prihananto, 2014).

Semakin maraknya penyalahgunaan teknologi, obat-obatan terlarang, minuman keras dan lain lain, hampir di semua kelompok usia mengakibatkan dekadensi moral yang menjauhkan kedekatan kepada Sang Pencipta. Maka perlu upaya yang dapat menangani persoalan tersebut, layanan yang diberikan secara sistematis, objektif dan terprogram dengan menggunakan pendekatan islam. Hal diatas sudah mejadi tugas utama bimbingan dan konseling untuk memfasilitasi konseli agar mampu beradaptasi, mengembangkan potensinya dengan mencapai tugas perkembangan yang menyangkut aspek fisik, emosi, intelektual sosial dan moral spiritual (D. P. dan Kebudayaan, 2007).

Selain itu, banyak konseli yang beragama islam yang di konseling dengan menggunakan pendekatan konseling sekuler cenderung kesulitan dalam membangun hubungan dan mempercayai konselornya (Inayat, 2007). Pelaksanaan layanan bimbingan dan konseling islam bukan hanya mengintegrasika nilai-nilai dalam ajaran agama islam, yang mengadopsi pendekatan barat lalu dimasukkan unsur keislaman. Tapi, menempatkan bimbingan dan konseling islam setara dengan pendekatan barat. Oleh karena itulah, sejak beberapa dekade ini perkembangan bimbingan dan konseling islam begitu pesat, dengan point of departure bimbingan 
dan konseling islam sebagai satu paradigma baru dalam pendekatan konseling.

\section{Penutup}

Pesatnya perkembangan zaman kadang berada diluar batas toleransi manusia, sehingga orang-orang yang tidak mampu menyesuaikan dirinya harus berurusan dengan stres, cemas dan situasi negatif lainnya. Keadaan tersebut membuat manusia hilang arah, tidak menyadari dirinya tersesat dan jauh dari Allah SWT. Orang-orang berikut menurut Al-Ghazali adalah orang-orang yang kesehatan mentalnya terganggu.

Hadirnya bimbingan dan konseling islam merupakan jawaban atas tantangan yang dihadapi manusia di zaman globalisasi. Mengembalikan dan menguatkan hubungan manusia dengan Allah SWT dan menyerahkan diri sepenuhnya kepadaNya serta mengevaluasi semua perbuatan yang pernah dilakukan adalah kunci keberhasilan layanan bimbingan dan konseling islam.

Meskipun perdebatan para pakar bimbingan dan konseling terus terjadi mengenai kelayakan integrasi spiritual dan agama dalam layanan konseling. Namun, perdebatan itu memberikan peluang bagi para pengembang keilmuan bimbingan dan konseling islam untuk terus melakukan penemuan yang berkontribusi dalam teori maupun praktiknya. Sampai saat ini bimbingan dan konseling islam merupakan salah satu pendekatan yang populer dan terbukti efektif dalam mengentaskan masalah-masalah yang dialami oleh konseli.

\section{Daftar Pustaka}

Abdullah, S. (2009). Islamic Counselling and Psychotherapy Trends in Theory Development. Retrieved March, 10, 2012.

Abu-Raiya, H. (2014). Western Psychology and Muslim Psychology in Dialogue: Comparisons Between a Qura'nic Theory of Personality and Freud's and Jung's Ideas. Journal of Religion and Health, 53(2), 326-338. https://doi.org/10.1007/s10943-012-9630-9

Anwar, M. F. (2015). Filsafat Manusia Dalam Bimbingan Konseling Islam. ORASI: Jurnal Dakwah Dan Komunikasi, 6(1). Diambil dari http://syekhnurjati.ac.id/jurnal/index.php/orasi/article/view/1407

Baqutayan, S. M. S. (2011). An innovative Islamic counseling. International Journal of Humanities and Social Science, 1(21), 178-183.

Brown, D. R., Carney, J. S., Parrish, M. S., \& Klem, J. L. (2013). Assessing Spirituality: The Relationship Between Spirituality and Mental Health. Journal of Spirituality in Mental Health, 15(2), 107-122. https://doi.org/10.1080/19349637.2013.776442

Burke, M. T., Chauvin, J. C., \& Miranti, J. G. (2005). Religious and spiritual issues in counseling: applications across diverse populations. New York: BrunnerRoutledge.

Cornish, M. A., \& Wade, N. G. (2010). Spirituality and Religion in Group Counseling: A Literature Review with Practice Guidelines. Professional Psychology: Research and Practice, 41(5), 398-404. https://doi.org/10.1037/a0020179

Djawad Dahlan, M. (1985). Beberapa Pendekatan Dalam Penyuluhan (Konseling): Psikoanalisa, Berpusat pada Klien, Terapi Tingkah Laku. CV Diponegoro.

Hanin Hamjah, S., \& Mat Akhir, N. S. (2014). Islamic Approach in Counseling. Journal of Religion and Health, 53(1), 279-289. https://doi.org/10.1007/s10943-0139703-4 
Henriksen, R. C., Polonyi, M. A., Bornsheuer-Boswell, J. N., Greger, R. G., \& Watts, R. E. (2015). Counseling Students' Perceptions of Religious/Spiritual Counseling Training: A Qualitative Study. Journal of Counseling \& Development, 93(1), 59-69. https://doi.org/10.1002/j.1556-6676.2015.00181.x

Inayat, Q. (2007). Islamophobia and the therapeutic dialogue: Some reflections. Counselling Psychology Quarterly, 20(3), 287-293. https://doi.org/10.1080/09515070701567804

Inayat, Q. (2010). The relationship between integrative and Islamic counselling. Counselling Psychology Quarterly, 14(4), 381-386. https://doi.org/10.1080/09515070110101478

Indonesia, M. P. dan K. R. (2014). Peraturan Menteri Pendidikan dan Kebudayaan Republik Indonesia Nomor 111 Tahun 2014. Jakarta. Diambil dari http://jdih.kemdikbud.go.id/new/public/assets/uploads/dokumen/permendik bud_tahun2014_nomor044.pdf

Johnson, R. (2013). Spirituality in Counseling and Psychotherapy: an Integrative Approach that Empowers Clients. Hoboken, New Jersey: John Wiley \& Sons, Inc.

Kamaruzzaman, K. (2017). Analisis Faktor Penghambat Kinerja Guru Bimbingan dan Konseling Sekolah Menengah Atas. Sosial Horizon: Jurnal Pendidikan Sosial, $3(2), 229-242$.

Kebudayaan, D. P. dan. (2007). Rambu-rambu Pelaksanaan Bimbingan dan Konseling pada Jalur Pendidikan Formal. Jakarta: Direktorat Jenderal PMPTK.

Kebudayaan, K. P. dan, \& Kependidikan, D. J. G. dan T. (2016). Panduan Operasional Penyelenggaraan Bimbingan dan Konseling. Diambil dari http://unw.ac.id/site/download/kerjasama/815e6212def15fe76ed27cec7a39 3d59/Panduan_Penyelenggaraan_BK_SMK.pdf

Keshavarzi, H., \& Haque, A. (2013). Outlining a Psychotherapy Model for Enhancing Muslim Mental Health Within an Islamic Context. International Journal for the Psychology of Religion, 23(3), 230-249. https://doi.org/10.1080/10508619.2012.712000

Leeming, D. A. (Ed.). (2014). Encyclopedia of Psychology and Religion. Boston, MA: Springer US. https://doi.org/10.1007/978-1-4614-6086-2

Lubis, S. A. (2011). Islamic Counseling: The Services of Mental Health and Education for People. Religious Education, 106(5), 494-503. https://doi.org/10.1080/00344087.2011.613347

Parker, S. (2011). Spirituality in Counseling: A Faith Development Perspective. Journal of Counseling \& Development, 89(1), 112-119.

Prihananto, M. (2014). Participant Observation dan Personal Documents dalam Penelitian Kualitatif BKI. Jurnal Bimbingan Dan Konseling Islam, 2(1), 48-64.

Robert, T., \& Kelly, V. A. (Ed.). (2015). Critical Incidents in Integrating Spirituality into Counseling. Alexandria, VA: American Counseling Association.

Rohman, A. (2016). Peran Bimbingan dan Konseling Islam Dalam Pendidikan. PROGRES, 4(1). Diambil dari https://www.publikasiilmiah.unwahas.ac.id/index.php/PROGRES/article/view $/ 1731$

S. S, A. (2011). Islamic theological and spiritual foundations of resilience: implications for counseling and psychotherapy with muslims. International Conference on the Psychology of Resilience.

Sauchelli, A. (2016). The Definition of Religion, Super-empirical Realities and Mathematics. Neue Zeitschrift für Systematische Theologie und 
Religionsphilosophie, 58(1). https://doi.org/10.1515/nzsth-2016-0005

Schilbrack, K. (2013). What isn't Religion? The Journal of Religion, 93(3), 291-318.

Subhi, M. R. (2016). Development of Islamic Counseling Concept (Spiritual Issues in Counseling). Jurnal Hisbah, 13(1). Diambil dari http://ejournal.uinsuka.ac.id/dakwah/hisbah/article/view/1012

Sutoyo, A. (2013). Bimbingan dan Konseling Islam (Teori dan Praktik). Yogyakarta: Pustaka Pelajar.

Zayed, T. M. (2017). Conceptual and Practical Understanding of Counseling in Islam. MOJC: Malaysia Online Journal of Counseling, 2(1). Diambil dari https://ejournal.um.edu.my/index.php/MOJC/article/view/5560 